\title{
Implications for bachelor of nursing programs when using student experience survey findings as an indicator of course quality
}

\section{AUTHORS}

MORGAN R SMITH RN, BN, MEd, PhD ${ }^{1}$

SARAS HENDERSON RN, MEd, PhD, FACN, SFHEA ${ }^{2}$

LAURIE GREALISH RN, PhD, FACN ${ }^{3}$
1 Adelaide Nursing School, University of Adelaide, South Australia.

2 Menzies Health Institute Queensland \& School of Nursing and Midwifery, Griffith University and the Hopkins Centre Research for Rehabilitation and Resilience.

3 Menzies Health Institute Queensland \& School of Nursing \& Midwifery, Griffith University and Gold Coast Health

\section{CORRESPONDING AUTHOR}

MORGAN R SMITH Adelaide Nursing School, Health and Medical Sciences building, University of Adelaide, South Australia 5005. Phone: +61 (08) 8313 0219. Email: morgan.r.smith@adelaide.edu.au

\section{ABSTRACT}

Objective: To discuss the implications of using student experience surveys to improve the quality of teaching and learning within bachelor of nursing programs in Australia.

Background: Australia's recent independent review of nursing education suggests that not all graduates are sufficiently prepared for their registered nurse role, indicating problems with program quality. Student experience surveys are widely used in course development processes.

Discussion: A reliance on student experience survey findings for course development may contribute to course changes based on student satisfaction that place overall graduate capability at risk. Because student experience surveys have design limitations, satisfaction only partially aligns with learning and learning outcomes, and students' subjective beliefs about self, nursing and learning potentially influence their survey responses, the exclusive use of student experience surveys in course development and teacher evaluations is contested.
Conclusion: Using student experience survey findings as an indicator of course quality has unacknowledged implications for bachelor of nursing programs. Findings from student experience surveys should be situated within a context of other elements or factors when making curriculum decisions. Teacher and course evaluations based primarily on student satisfaction can have unintended consequences for course content, course delivery, student learning and learning outcomes and ultimately impact on the reputation of the university.

What is already known about the topic?

- Student experience surveys are used widely in higher education in Australia.

- Universities monitor student satisfaction as an indicator of course quality through student experience surveys.

What this paper adds:

- The relationship between the characteristics of course quality and student satisfaction require further exploration in practice-focused programs such as nursing. 
- The governance of course quality using student experience as a primary indicator may unintentionally limit course development, catering to student preferences rather than focusing on learning experiences that are required for graduate capability.
Keywords: student experience, satisfaction, nursing, course evaluation

\section{INTRODUCTION}

Graduates of bachelor of nursing programs must be able to meet the complex healthcare needs of a diverse and ageing population. A recent review into nurse education in Australia suggested that there was a belief amongst stakeholders that not all graduates are adequately prepared for a registered nurse role, recommending the development of external mechanisms to manage this issue. ${ }^{1}$ However, issues relating to the quality of nursing graduates can, and should, be addressed within bachelor of nursing programs.

While focused on quality graduates, Australian universities are interested in high student enrolments and associated revenue. As such, satisfied students, including nursing students, are important. In a competitive higher education environment, universities rely on students reporting positively on their educational experiences to enhance the reputation of each institution and to attract both local and international students. ${ }^{2,3}$ Further, with government funding linked to student enrolments, attracting future students is critical for university survival. ${ }^{4}$ Understanding students' satisfaction with their teachers and courses is important to enhance university business.

In writing this article, the authors intend to provoke debate around the dominant use of student satisfaction as the indicator of quality in bachelor of nursing programs. A poststructural approach was adopted to explore the unintended effects of student satisfaction as a primary indicator of bachelor of nursing program teaching and learning quality. ${ }^{5}$ A post-structural perspective challenges knowledge as absolute and focuses on re-thinking dominant discourses. ${ }^{6}$ In this case, the privileging of student satisfaction within the discourse of program quality.

\section{STUDENT EXPERIENCE SURVEYS IN AUSTRALIAN HIGHER EDUCATION}

Student experience surveys enable universities to acquire information on student satisfaction. 'Student satisfaction refers to the favourability of a student's subjective evaluation' 7(p.3545) in relation to their higher education experience overall or to components of the degree. While the terms 'course' and 'program' and 'course' and 'subject' or 'unit' may be used interchangeably, ${ }^{8}$ for the purpose of this paper the Australian
Nursing and Midwifery Accreditation Council (ANMAC) 9 approved terminology will be used. A 'program' refers to the degree in its entirety and 'courses' refer to components of a program. ${ }^{9}$ Courses are embedded within programs.

Three main student experience surveys are used in Australian universities: Student Experience Survey, the Course Experience Questionnaire (part of the Graduate Outcomes Survey) and internally administered student experience surveys..$^{10}$ Each of these surveys will be discussed next.

\section{STUDENT EXPERIENCE SURVEY}

The Student Experience Survey is a national survey of all university undergraduate programs and is conducted annually. It assesses students' satisfaction with the overall quality of the educational experience, teaching quality, learner engagement, learning resources, student support and skills development, using Likert scales. All students in all programs in all universities respond to identical survey items. The percentage of students providing positive feedback is reported on the national Quality Indicators of Learning and Teaching website.The results, in the form of a star system, are also used to rank universities in the Good Universities Guide. A high star ranking is considered desirable for attracting future students and as a quality education indicator. ${ }^{11}$

\section{COURSE EXPERIENCE QUESTIONNAIRE}

The Australian government also promote the Course Experience Questionnaire, which is a measure of student satisfaction with the overall program. It is circulated to all recent university graduates, noting that not all graduates complete the survey. The Course Experience Questionnaire includes one question on overall satisfaction with their program, six questions on teaching, and five questions on generic skills. ${ }^{11}$

\section{INTERNALLY ADMINISTERED STUDENT EXPERIENCE SURVEYS}

Australian universities commonly use internal survey tools to measure the students experiences of teaching and courses although how this is done varies across institutions. ${ }^{10}$ Instruments consist of mandatory fixed questions, which are the same across the institution; and open-ended questions to 
identify what works well and what could be improved. Some institutions enable academics to select optional additional items from a database.

Internal student experience surveys are commonly administered centrally, with data provided to academic staff following the assessment period in each semester. These instruments are invariably used for routine evaluation to assure the University and Program Director that the course is contributing to learning in the program as intended, to encourage academic staff to engage in scholarship of teaching through reflection on feedback, to link student feedback to academic staff promotion, and provide a mechanism for students to provide input into quality of teaching and learning.

\section{DISCUSSION}

In addition to established concerns about adequate sample size to reduce response bias, ${ }^{12}$ student experience surveys have other limitations. Three limitations are identified: student experience surveys may not be fit for purpose; alignment between student satisfaction and learning is partial; and student satisfaction is influenced by personal beliefs and values. Due to the limitations of student experience surveys, when academic staff make changes to their courses based on survey results, there may be unintended consequences for student learning.

\section{STUDENT EXPERIENCE SURVEYS MAY NOT BE FIT FOR PURPOSE}

Student experience surveys were designed to gauge student perspectives of the educational environment at the program level. ${ }^{2}$ However, core questions from national surveys are used for internal surveys. ${ }^{10}$ While in some universities academics may be able to add additional questions, the core questions may not be relevant to unique disciplinary course requirements.

Generic measures tend not to capture student experiences achieved in non-university, ie. workplace, settings. The assumption inherent in student experience surveys is that students learn predominantly in the university environment. ${ }^{13}$ Bachelor of nursing programs require students to learn in both the university and the nursing workplace with students spending at least 800 hours in a variety of healthcare settings. ${ }^{14}$ Health settings are varied and include, but are not limited to, hospitals, rural and remote clinics and community settings. ${ }^{14}$ Different measures for nursing student experience on work-based placement exist, ${ }^{15}$ but are not automatically included in centrally managed surveys. How nursing students' placement experiences impact on their responses to internal university and national surveys is unknown, suggesting an area for future research. placement experiences constituting a large part of the program. The usefulness of the findings of student experience surveys for nursing courses is dependent on nursing students' perceiving the survey as relevant to their learning. The standard surveys are not fit for purpose. Even if the lecturer is able to selects additional questions on workplace experiences from a databank, the survey findings may not accurately indicate the alignment between the course and program expectations and outcomes. It is timely for nurse academic leaders to partner with education leaders to develop student experience surveys that are more sophisticated and able to capture students' placement as well as classroom experiences.

\section{ALIGNMENT BETWEEN STUDENT SATISFACTION AND LEARNING IS PARTIAL}

There is partial alignment between student satisfaction and learning, with potential implications for nursing student graduate outcomes. Learning requires student engagement, often through emotions such as excitement and high interest or frustration and difficulty, with 'disorienting dilemmas' considered important to facilitate learning. ${ }^{16}$ Negative feelings of frustration may facilitate learning but translate to students' feeling unsatisfied in surveys. If effective learning requires a degree of psychological discomfort, then some degree of dissatisfaction may be necessary for learning to be effective. ${ }^{17}$

In the example of bioscience, a systematic review of interventions to improve learning found that the focus on student satisfaction with supportive learning interventions was inadequate and recommend refocusing evaluation on acquisition of bioscience knowledge and understanding at graduation..$^{18}$ In an in-depth study of nursing students' learning experiences, students indicated that course content, which is perceived as complex, such as bioscience, may result in dissatisfaction with their learning. ${ }^{17}$ Dissatisfaction on surveys may indicate that students find the content complex, rather than accurately reflect their learning.

Satisfaction may also be low when nursing students perceive content to be less relevant. A systematic review of pedagogical strategies to teach nursing students evidencebased practice found that those students who had difficulty understanding the relationship between research findings and nursing practice may indicate dissatisfaction with research courses. ${ }^{19}$ Students may fail to understand how certain knowledge will assist them in their future role as a registered nurse and become dissatisfied with their learning. ${ }^{17}$ Students must gain knowledge of both research and other areas fundamental to nursing if they are to be prepared for their future role as a registered nurse, ${ }^{14}$ but may not realise the value of learning complex knowledge and skills until later in the program or after they graduate. 
Personal perceptions of satisfaction with learning may not align with external assessments of performance. In an evaluation of a nursing communication skills training course, researchers found that self-rated ability and satisfaction were linked, but that neither was linked to objective assessment by an educator. ${ }^{20}$ Nursing students who were most satisfied tended to rate their communication skills more highly, but on objective assessment were found to perform no better than students who rated their communication skills lower. ${ }^{20}$ Therefore, the alignment between student satisfaction and learning is partial at best.

In summary student satisfaction with their experiences may only be partially aligned with student learning. Where evidence-based teaching and learning strategies lead to students learning complex content or material that is not perceived as relevant, this learning may reflect negatively in teaching or course experience scores.

As indicated earlier, one purpose of conducting internal university experience surveys for teaching and courses is to engage staff in the scholarship of teaching, providing material for reflection and course development. When student satisfaction does not align fully with learning, the risk of making changes to teaching strategies and course content based on survey results only may lead to unintended consequences for the curriculum and graduate outcomes. Generic academic skills courses for new nurse academics should address the social and political practice, as well as pedagogical, elements of curriculum design in higher education. While a scholarship of teaching exists in universities, the unique elements in nursing programs require academic nurses to be critical of the alignment of student experience surveys and learning. There is no national community of nurse academics, where new academic nurses can enter into scholarly debate about the merits of student experience surveys and other higher education policies.

\section{STUDENT SATISFACTION IS AFFECTED BY PERSONAL BELIEFS AND VALUES}

Satisfaction is a highly subjective concept, and therefore influenced by factors unique to each individual. As student diversity increases ${ }^{21}$ their personal backgrounds and expectations about nursing and nursing knowledge will impact how they experience satisfaction with the program.

In a grounded theory study of nursing students' satisfaction with learning, learning was conceptualised as a journey, where student satisfaction was not stable or directly related to a teaching strategy or course. ${ }^{17}$ Rather, satisfaction ebbed and flowed, with intense emotional experiences of joy, irritation, fear and hope. ${ }^{17}$ Through each student's unique nursing journey, their experiences of satisfaction, dissatisfaction or ambivalence with learning were also unique. ${ }^{17}$ Factors that may influence student satisfaction include available time to study, in the context of work-life balance and personal beliefs about historical models of nursing education. ${ }^{17}$
Nursing students who need to work while studying may be less satisfied with their learning experience. For example, in a study of student learning in the workplace, researchers found that nursing students who worked more than 16 hours per week were less satisfied with their placement than students who worked less. ${ }^{22}$ While satisfaction with placement may be negatively affected by working, it is not clear whether students learned valued knowledge, understanding and skills while on these placements. Further research into the relationship between personal characteristics, such as the need to work, satisfaction, and learning are required.

Student satisfaction may be influenced by personal beliefs about the kind of nurse they want to be. ${ }^{17}$ In Australia, nursing continues to be conceptualised in the traditional way, as a practical profession, where nursing education privileges 'the pragmatic over the esoteric, the practical over

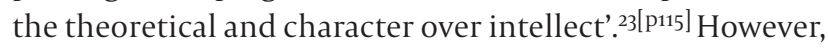
in today's climate of continuous change and development, graduates are expected to be flexible, responsive and innovative in response to changing community need. ${ }^{14}$ Students who expect pragmatic, may be dissatisfied with esoteric, and this may be reflected negatively in experience surveys.

In summary, students' personal situation, life experience, beliefs and expectations influence their satisfaction with learning. With an increasingly diverse student population, nursing academics seeking career promotion are expected to design multiple teaching strategies to support students' diverse situations and learning preferences, while at the same time trying to pursue their own research. For academic staff, the challenge of balancing the triumvirate of teaching, research, and service in order to progress their careers, can be overwhelming. ${ }^{24}$

\section{IMPLICATIONS FOR TEACHING AND LEARNING IN BACHELOR OF NURSING PROGRAMS}

While nationally administered surveys for student and course experience are recognised as important for benchmarking the higher education sector, internally administered student experience surveys have implications for teaching and learning in bachelor of nursing programs. Providing students an opportunity to provide input into the quality of teaching and learning is laudable but carries inherent, and implicit risks. Surveys not being fit for purpose, partial alignment between student satisfaction and learning, and the impact of personal beliefs and values on satisfaction raise implications for teaching and learning.

Generic survey questions in internal surveys are not fit for purpose when used within courses. Rather, the inclusion of these questions is to align teacher practice with the university goal of higher student satisfaction scores. When using questions based on the Course Experience Questionnaire as the fixed questions in the internal surveys, alignment is achieved. When student satisfaction at course 
level is low, academic staff and their managers become focused on how to address the low scores. The implication for curriculum design is that academic staff may undertake course re-design to enhance appeal of the courses for future students. However, making the course appealing and improving learning may not be the same. Further investigation into how academic staff use internal survey findings in curriculum design is required.

While it is widely accepted that student satisfaction can indicate learning, the alignment is partial rather than complete. Focusing on evidence-based teaching when students may be more satisfied with less challenging approaches to learning can pose dilemmas for staff aiming to improve student satisfaction. Higher education experts suggest that satisfaction surveys have placed pressure on academics to gain high ratings but without necessarily focusing on doing so by increasing teaching standards, assessment and learning outcomes..$^{10}$ Avoiding these negative consequences of student satisfaction surveys can result in nurse academics continuing with traditional teaching approaches and avoiding innovative ones. ${ }^{25}$

In addition to the partial alignment between student satisfaction and learning, there is widespread evidence of low response rates to surveys, with associated bias. ${ }^{12}$ Given these examples, and their implications for learning, we suggest that nurse academics and university management should ensure that student satisfaction data is used in combination with other evidentiary sources such as student grades, engagement in course related learning activities, and performance in work-based experiences.

Students are diverse in their backgrounds, experiences, beliefs, values and expectations, and as such will have unique experiences of satisfaction. However, nurse academics are held to account for student satisfaction. Evidence of positive student attitudes and satisfaction are often required for staff promotions, awards, performance review and contract renewal. ${ }^{10,25}$ Therefore, in order to remain employed, or progress their careers, staff are highly motivated to ensure students are satisfied with their educational experience.

Retaining courses, or course content, in the curriculum where students have indicated low satisfaction can pose a dilemma to staff interested in enhancing student satisfaction. It might enhance student satisfaction, and therefore more positive responses to surveys, if course content that students perceived as less important was reduced or removed from the curriculum. For example, how to manage low satisfaction scores on more problematic courses, such as complex courses in bioscience and or esoteric nursing research/evidencebased practice theory. In this situation, there is conflict between an action that may enhance student satisfaction, i.e. remove courses with low satisfaction, and one that might enhance learning, and ultimately nursing practice following graduation, i.e. keep the course despite low satisfaction scores. Rather than removing the course, nurse academics may benefit from collaborative reflection with more experienced academic mentors, ${ }^{24}$ in order to identify changes that can leave the overall curriculum intact.

Enabling students with complex lives and multiple personal commitments to acquire sufficient learning to provide effective nursing care on graduation while also ensuring they respond positively to student satisfaction surveys has implications for teaching and learning. Any expressed dissatisfaction is potentially problematic for nurse academics when it impacts on their career opportunities and progression. Balancing the need for students to be satisfied with their education and learn what is required for nursing practice provides nurse academics with serious challenges in the current higher education environment.

\section{CONCLUSION}

In preparing this argument for collegial consideration, we have aimed to be provocative, providing an alternative discourse for the use of student experience questionnaires in course development. The quality of nursing graduates is dependent on the quality of the course and how that quality is determined requires continual review. This argument is inductive in nature, reflecting the purpose of providing an alternative discourse. As an inductive argument, it can be considered an educated opinion piece, which adds to the rich discourse of course development in nursing education.

Using examples from nursing literature, we argue that using student experience surveys in undergraduate nursing programs may result in unintended outcomes for learning with unanticipated consequences for employers of nursing graduates and consumers of care. Graduates of bachelor of nursing programs are not simply consuming a program of education, they are preparing themselves for practice as a registered nurse. The current use of student satisfaction as an indicator of course quality is not producing graduates that are meeting industry requirements. ${ }^{1}$ While the transfer of nursing education into the higher education sector was widely supported by nursing's professional bodies, it is timely for the profession's leaders to review the use of student satisfaction in course quality and find innovative ways to support nurses who are also academics - a specialty of its own.

\section{RECOMMENDATIONS}

In light of the discussion above, we recommend the following actions be implemented to address the use of generic internally administered student experience surveys for courses within a bachelor of nursing:

1 Australian Nursing and Midwifery Federation could explore a partnership with the National Tertiary Education Union so that the implications of university policy on nurse and midwifery curricula can be more specifically addressed. 
2 Deans of Nursing and Midwifery could consider how to manage student satisfaction related tensions between studying in an academic context while maintaining a program that requires placement in healthcare services to enhance learning and graduate outcomes.

3 Generic academic skills courses provided for nurses who are new to the academy must address the socio-political, as well as pedagogical, elements of curriculum design and development in order to critically evaluate higher education policy.

4 Australian College of Nursing could develop an academic nurse interest group, where nurse academics can develop collegial relationships, undertake collaborative research into educational practices and policies, and enter into scholarly debate about the merits of higher education policies, such as student experience surveys.

5 Further research into the value of generic student surveys within the broader context of a capable nursing graduate is required.

Funding support: The research did not receive any specific grant from funding agencies in the public, commercial, or not-for-profit sectors.

Declaration of conflicting interests: No conflicts of interest exist.

\section{REFERENCES}

1 Department of Health. Educating the nurse of the future report of independent review of nursing education. Australian Government. 2019. [cited 28 December 2019]. Available from: https://www.health.gov.au/resources/publications/educatingthe-nurse-of-the-future?utm source=miragenews\&utm medium=miragenews\&utm campaign=news.

2 Talukdar J, Aspland T, Datta P. Australian higher education and the course experience questionnaire: insights, implications and recommendations. Australian Universities Review. 2013; 55(1):27-35

3 Shah M, Nair CS. The changing nature of teaching and unit evaluations in Australian universities. Qual Assur Educ. 2012; 20(3):274-288.

4 Department of Education. Funding Australian government. 2018. [Cited 28 October 2019]. Available from: https://www.education.gov.au/funding

5 M. Murphy. Social Theory and Education Research: Understanding Foucault, Habermas, Bourdieu and Derrida. Oxfordshire (England): Taylor \& Francis Group; 2013.

6 O'Keefe S. Skerritt C. Exploring teacher identity using poststructural tools. Int J Res Meth Educ. 2020.

7 Lapkin S, Levett-Jones T. A cost-utility analysis of medium vs. high-fidelity human patient simulation manikins in nursing education. J Clin Nurs. 2011; 20 (23-24): 3543-52.

8 Tertiary Education Quality and Standards Agency. Glossary of terms in Part A of the Higher Education Standards Framework 2015. 2015. [Cited 3 July 2020]. Available from: https://www.teqsa.gov.au/glossary-terms-part-highereducation-standards-framework-2015.
9 Australian Nursing and Midwifery Accreditation Council. ANMAC glossary. 2016. [Cited 3 July 2020]. Available from: https://www.anmac.org.au/glossary.

10 Shah M, Nair CS, Richardson JTE. Measuring and enhancing the student experience. Cambridge (MA): Chandos Publishing; 2016.

11 Social Research Centre. Quality Indicators for Learning and Teaching (QILT). 2019. [Cited 16 June 2019]. Available from http://www.qilt.edu.au.

12 Goos, M, Salomons A. Measuring teaching quality in higher education: assessing selection bias in course evaluations. Res High Educ. 2017; 58 (4):341-364.

13 Rogers J, Smith, M. Demonstrating genuine interest in students' needs and progress: implications for student satisfaction with courses. J Appl Res High Educ. 2011; 3(1):6-13.

14 Australian Nursing and Midwifery Accreditation Council. Registered nurse accreditation standards. 2019. [Cited 29 January 2020]. Available from: https://www.anmac.org.au/sites/default/files/documents/ registerednurseaccreditationstandards2019.pdf.

15 Henderson A, Cooke M, Creedy DK, Walker R. Nursing students' perceptions of learning in practice environments: A review. Nurs Educ Today. 2011; 32 (3):299-302.

16 McAllister M. STAR: A transformative learning framework for nurse educators. J Transform Educ. 2011; 9(1):42-58

17 Smith M, Grealish L, Henderson S. Shaping a valued learning journey: student satisfaction with learning in undergraduate nursing programs, a grounded theory study. Nurse Educ Today. 2018; 64:175-179.

18 McVicar A, Andrew S, Kemble R. Biosciences within the preregistration (pre-requisite) curriculum: an integrative literature review of curriculum interventions 1990-2012. Nurse Educ Today. 2014; 34(4):560-568.

19 Aglen B. Pedagogical strategies to teach bachelor students evidence-based practice: a systematic review. Nurse Educ Today. 2016; 36:255-263.

20 Mullan BA, Kothe EJ. Evaluating a nursing communication skills training course: the relationships between self-rated ability, satisfaction, and actual performance. Nurse Educ Prac. 2010; 10(16):374-378

21 Salamonson Y, Ramjan L, Lombardi L, Lanser LH, Fernandez R, Griffith R. Diversity and demographic heterogeneity of Australian nursing students: a closer look. Int Nurs Rev. 2012; 59(1):59-65

22 Salamonson Y, Bourgeois S, Everett B, Weaver R, Peters K, Jackson D. Psychometric testing of the abbreviated Clinical Learning Environment Inventory (CLEI-19). J Adv Nur. 2011; 67(12):2668-2676.

23 Walker K, Holmes C. 'The 'order of things': Tracing a history of the present through a re-reading of the past in nursing education. Contemp Nurse. 2008; 30(2):106-118

24 McDermid F, Peters K., Daly J, Jackson D. Developing resilience: stories from novice nurse academics. Nurse Educ Today. 2016; 38:29-35

25 Biggs J, Tang C. Teaching for quality learning at university. 4th ed. Maidenhead (England): McGraw Hill Society for Research into Higher Education \& Open University Press; 2011. 